\title{
STUDI PENGEMBANGAN LAHAN RAWA LEBAK POLDER ALABIO HULU SUNGAI UTARA KALIMANTAN SELATAN
}

\author{
Nadya Ul-Haq Mahmud ${ }^{1)}$ \\ 1) Teknik Lingkungan, Universitas Lambung Mangkurat, Banjarbaru, Kalimantan \\ Selatan \\ nadyaulhaq20@gmail.com
}

\begin{abstract}
The potential and area of swamps in Indonesia are very large, but the development of swamps is still small. The key success factor in swamps development lies in the water management system. The Alabio polder is the result of the development of a nontidal swamp with a polder system with an area of \pm 6000 Ha located in the Alabio area, Danau Panggang District, South Kalimantan. Until now, Polder Alabio has not been working optimally, so rice production in this land has not been as expected. This paper aims to identify problems in the development of the Alabio Polder nontidal swamp. The method used in this study is to use literature studies taken from various scientific sources, either in the form of scientific articles, activity reports/studies related to the Alabio Polder. The study results showed that the water management at the Alabio Polder is still not functioning optimally. The main problems in the development of the Alabio Polder are the irrigation, drainage, and water structures that are not functioning properly, as well as the maintenance that has not been carried out routinely and properly. Irrigation channels, drainage, and water structures that do not function properly cause the quantity of water (discharge) to not be flowed properly to the entire land so that it also impacts the water quality in the land which is not good. Some solutions that can be done to overcome the problems at the Alabio Polder are to carry out regular and periodic repairs and maintenance of irrigation and drainage channels as well as maintenance of water buildings in the Alabio Polder.
\end{abstract}

Keywords: drainage, irrigation, Alabio Polder, nontidal swamp, water management 


\begin{abstract}
ABSTRAK
Potensi dan luas lahan rawa di Indonesia sangat besar, namun pengembangan lahan rawa masih sedikit. Faktor kunci keberhasilan dalam pengembangan lahan rawa terletak pada sistem tata kelola air. Polder Alabio merupakan hasil pengembangan lahan rawa lebak sistem polder dengan luas \pm 6000 Ha yang berada di daerah Alabio Kecamatan Danau Panggang, Kalimantan Selatan. Sampai sekarang Polder Alabio masih belum bekerja dengan maksimal, sehingga produksi padi di lahan ini belum seperti yang diharapkan. Tulisan ini bertujuan untuk mengidentifikasi permasalahan pada pengembangan lahan rawa lebak Polder Alabio. Metode yang digunakan pada studi ini adalah menggunakan studi literatur yang diambil dari berbagai sumber ilmiah, baik berupa artikel ilmiah, laporan kegiatan/studi terkait dengan Polder Alabio. Hasil studi menunjukkan bahwa pengelolaan air pada Polder Alabio masih belum berfungsi secara optimal. Permasalahan utama pada pengembangan Polder Alabio adalah pada sistem saluran irigasi, drainase dan bangunanbangunan air yang belum berfungsi dengan baik, serta pemeliharaan yang belum dilakukan dengan rutin dan baik. Saluran irigasi, drainase dan bangunan air yang tidak berfungsi dengan baik menyebabkan kuantitas air (debit) belum bisa dialirkan dengan baik pada seluruh lahan sehingga berdampak juga pada kualitas air di lahan yang kurang baik. Beberapa solusi yang dapat dilakukan untuk mengatasi permasalahan pada Polder Alabio adalah dengan melakukan perbaikan dan pemeliharaan secara rutin dan berkala pada saluran irigasi dan saluran drainase serta pemeliharaan terhadap bangunan-bangunan air yang ada di Polder Alabio tersebut.
\end{abstract}

Kata kunci: drainase, irigasi, Polder Alabio, rawa lebak, tata kelola air. 


\section{PENDAHULUAN}

Menurut Permen PUPR Nomor 29 Tahun 2015, rawa merupakan wadah air beserta air dan daya air yang terkandung didalamnya, tergenang secara terus menerus atau musiman, yang terbentuk secara alami pada lahan yang relatif datar ataupun cekung dengan endapan mineral atau gambut, serta ditumbuhi oleh vegetasi, yang merupakan suatu ekosistem. Lahan rawa juga dapat diartikan sebagai lahan yang tergenang air secara musiman ataupun permanen serta ditumbuhi oleh vegetasi yang sesuai dengan ekosistem tersebut (Irwandi, 2015). Indonesia memiliki lahan rawa dengan luas sekitar 33.4 juta (Suriadikarta, 2012). Lahan ini terdiri dari sekitar 20 juta hektar berupa rawa pasang surut dan 13 juta hektar lainnya berupa lahan rawa lebak. Lahan rawa ini memiliki potensi yang sangat besar dalam membantu aktivitas pertanian di Indonesia. Selain digunakan sebagai lahan pertanian, lahan rawa juga dapat membantu mengisi ketersediaan air. Hal ini karena lahan rawa mengandung banyak air yang dapat dimanfaatkan sebagai air irigasi.

Lahan rawa di Kecamatan Danau Panggang, Sungai Pandan dan Babirik Kabupaten Hulu Sungai Utara Provinsi Kalimantan Selatan termasuk jenis lahan rawa lebak. Rawa lebak di daerah ini digunakan untuk mengairi daerah irigasi seluas 6000 hektar yang berisi tanaman padi dan palawija (Sulaeman, Poggio, Minasny, \& Nursyamsi, 2018). Sistem tata air di daerah ini menggunakan sistem polder dan disebut sebagai Polder Alabio.

Pengelolaan air atau tata kelola air merupakan salah satu kunci keberhasilan dalam pengembangan/pemanfaatan lahan rawa lebak untuk pertanian. Polder Alabio merupakan sistem polder tertua yang berada di Kalimantan dan dibangun pada masa Belanda. Penggunaan sistem polder sudah dimulai sejak tahun 1950-an (Noor, Anwar, \& Kartiwa, 2019). Sistem polder adalah pengelolaan air dengan membangun tanggul di sekeliling daerah dalam skala luas (5.000 - 10.000 hektar). Sistem polder juga dapat diartikan sebagai sistem penanggulangan banjir dengan memisahkan sistem hidrologi suatu daerah dengan daerah sekitarnya (Zulfan \& Hana, 2013).

Sistem polder berfungsi untuk memasukkan dan mengeluarkan air agar dapat mempertahankan muka air sesuai dengan keperluan. Tetapi pada daerah studi, fungsi dari sistem polder tidak berjalan dengan semestinya. Hal ini karena terjadinya kehilangan air pada saluran irigasi yang sangat besar, banyak pintu tanggul yang sengaja terbuka dan volume 
saluran drainase semakin mengecil karena adanya sedimentasi. Akibatnya air akan tergenang pada satu daerah dan pencucian air berupa proses keluar masuk air tidak berjalan dengan baik. Jika terus dibiarkan maka akan berakibat pada memburuknya kualitas air rawa pada daerah studi. Gambar 1 dan Gambar 2 menyajikan kondisi Polder Alabio.

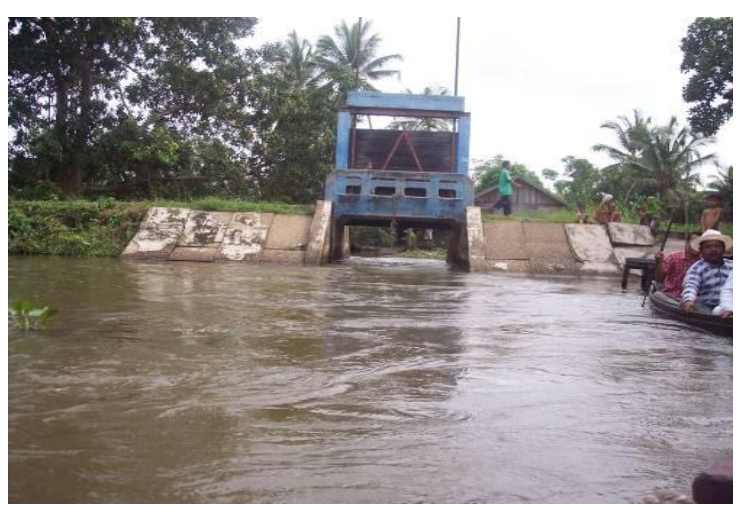

Gambar 1. Pintu Tanggul yang Terbuka di Polder Alabio

(Sumber: Anonim, 2015b)

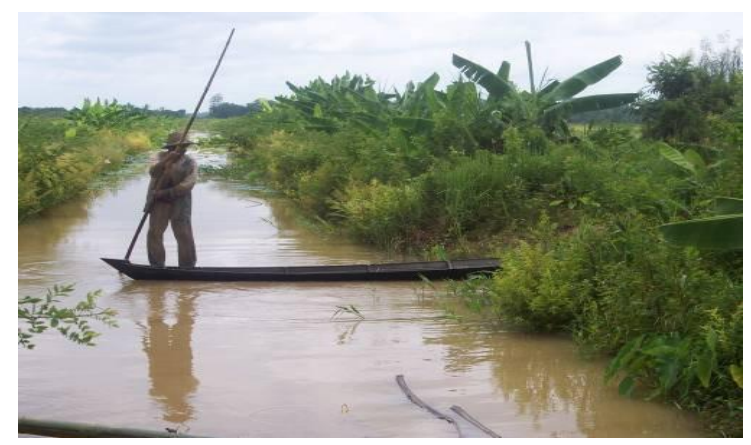

Gambar 2. Sedimentasi pada Saluran Irigasi di Polder Alabio (Sumber: Anonim, 2015b)

Polder Alabio merupakan salah satu pengembangan sistem polder tertua dan menjadi kebanggaan pengembangan lahan rawa lebak di Indonesia terutama Propinsi
Kalimantan Selatan Namun demikian, sampai sekarang Polder Alabio masih belum berfungsi dengan baik, karena ketersediaan air masih belum sepenuhnya terpenuhi dan beberapa prasarana fisik yang tidak berfungsi dengan baik, sehingga produksi padi pada lahan ini belum seperti yang diharapkan. Oleh karena itu, perlu dilakukan studi untuk mengidentifikasi beberapa permasalahan yang dihadapi pada pengembangan lahan rawa lebak Polder Alabio sehingga diharapkan hasil pertanian pada Polder Alabio menjadi lebih besar.

\section{KAJIAN PUSTAKA}

\subsection{Dasar Lahan Rawa}

Indonesia memiliki lahan rawa dengan luas sekitar 33.4 juta hektar (Suriadikarta, 2012). Lahan ini terdiri dari sekitar 20 juta hektar berupa rawa pasang surut dan 13 juta hektar lainnya berupa lahan rawa lebak. Lahan rawa ini memiliki potensi yang sangat besar dalam membantu aktivitas pertanian di Indonesia. Lahan rawa yang memiliki potensi ini umumnya berupa rawa tipis yang tetap bersifat hidrofilik. Hidrofilik merupakan suatu ikatan yang memiliki kemampuan untuk mengikat air dengan baik (Fuadi, Daud, \& Peratenta, 2015). Sedangkan lahan rawa yang berupa rawa tebal akan sangat tidak cocok untuk digunakan sebagai lahan pertanian. 
Lahan rawa adalah lahan yang memiliki genangan dalam kurun waktu tertentu yang diakibatkan oleh terhambatnya drainase. Rawa adalah istilah atau sebutan untuk daerah atau tempat yang tergenang oleh air dan bersifat secara musiman ataupun secara permanen yang ditumbuhi oleh tanaman tertentu. Menurut Genangan air pada lahan rawa biasanya hanya berupa genangan dangkal. Genangan ini dapat disebabkan oleh pasang surut air laut ataupun karena hujan.

Menurut Peraturan Menteri No 29 Tahun 2015, rawa terbagi menjadi 2 yaitu rawa pasang surut dan rawa lebak. Rawa pasang surut adalah rawa yang berada dipinggir pantai dan terpengaruh terhadap pasang surut air laut. Sedangkan rawa lebak adalah rawa yang berada jauh dari pantai dan berada di kawasan tanah rendah yang tergenang oleh air karena luapan air sungai dan hujan yang tergenang secara periodik atau menerus. Lahan rawa lebak terbagi menjadi 3 bagian yaitu bagian pematang atau lebak dangkal, lebak tengahan dan lebak dalam (Anonim, 2015a).

Diantara kedua lahan rawa, lahan rawa lebak adalah jenis lahan yang berpotensi sebagai penghasil pangan di Indonesia. Lahan rawa ini memiliki berbagai macam manfaat yang akan sangat membantu untuk kelangsungan hidup manusia. Selain digunakan sebagai lahan pertanian, lahan rawa juga dapat membantu mengisi ketersediaan air. Hal ini karena lahan rawa mengandung banyak air yang dapat dimanfaatkan sebagai air irigasi tetapi tetap dengan menggunakan bantuan teknologi pengelolaan air. Teknologi pengelolaan air akan dapat membantu sebagai penyetor air pada musim kemarau. Sehingga pada musim hujan lahan tidak akan kebanjiran dan pada musim kering lahan akan mendapat pasokan air yang cukup (Djamhari, 2009). Manfaat lain dari rawa adalah menggunakannya sebagai budidaya air tawar. Tetapi manfaat ini biasanya hanya dapat dijalankan pada rawa lebak dalam.

\subsection{Sistem Polder}

Sistem polder merupakan cara penanganan masalah banjir yang memiliki bangunan fisik meliputi kolam retensi, pompa air, sistem drainase, tanggul yang mengelilingi area dan pintu air (Rianto, 2012). Sistem ini mampu mengendalikan banjir serta dapat sekaligus menjadi obyek wisata ataupun lahan pertanian. Tetapi sebaik dan secanggih apapun sistem ini, akan ditemukan beberapa kelemahan dari penggunannya. Gambar 3 menyajikan bentuk sistem polder.

Sistem polder memiliki kekurangan dimana biaya yang diperlukan untuk 
menjalankan sistem ini sangatlah besar dan dalam waktu yang lama. Biaya ini akan digunakan untuk pembebasan tanah, pembangunan fisik dan pengadaan serta perawatan mesin-mesin dan peralatan. Oleh karena itu harus dilakukan pemeliharaan yang teratur dan sesuai dengan standar agar dapat bertahan dalam jangka waktu yang lama.

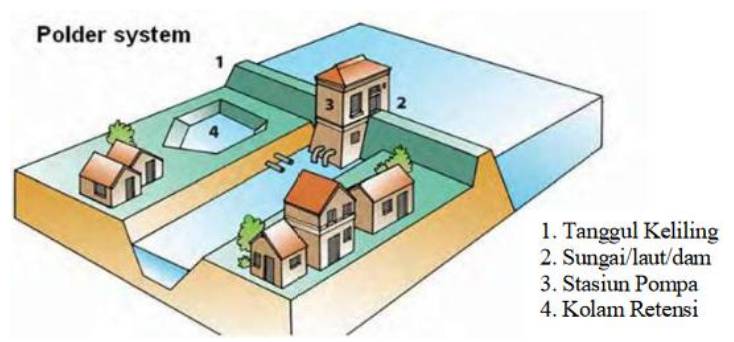

Gambar 3. Sistem Polder

(Sumber: Solikin, Suhartanto, \& Haribowo, 2017)

\section{METODE PENELITIAN}

\subsection{Prosedur Pengumpulan Data}

Pada studi ini, data-data yang dikumpulkan berupa data primer dan sekunder, namun data sekunder yang lebih banyak. Data primer diperoleh dengan melakukan survei di lokasi, hanya untuk mengetahui kondisi saluran dan bangunan air pada Polder Alabio. Data-data sekunder yang dikumpulkan berupa laporan hasilhasil studi yang telah dipublikasikan terkait dengan pengembangan lahan rawa dan secara khusus mengenai pengembangan Polder Alabio.

\subsection{Metode Analisis Data}

Data-data yang telah dikumpulkan selanjutnya dianalisis sehingga bisa dibahas dan diperoleh jawaban untuk kegiatan studi ini. Analisis data dilakukan dengan mengkompilasi data-data yang dikumpulkan dari hasil-hasil studi yang telah dilakukan dan telah dipublikasikan.

\section{HASIL DAN PEMBAHASAN}

Lokasi studi berada pada Kecamatan Danau Panggang, Sungai Pandan dan Babirik Kabupaten Hulu Sungai Utara Provinsi Kalimantan Selatan. Lebih tepatnya berada di daerah Alabio yang sekarang bernama Kecamatan Sungai Pandan, Kalimantan Selatan. Lokasi wilayah studi yaitu Polder Alabio ditunjukkan pada Gambar 4.

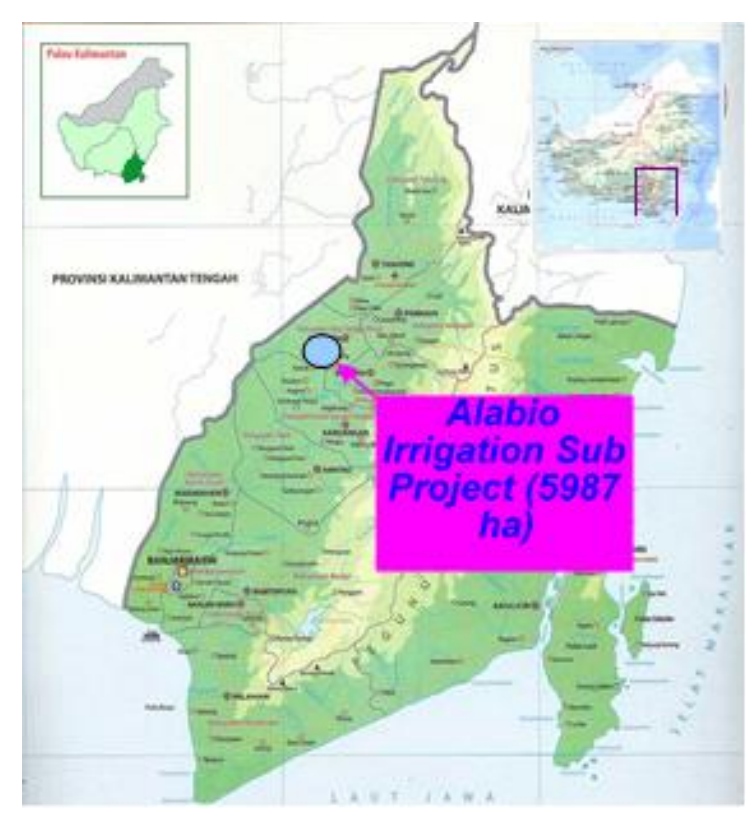

Gambar 4. Daerah Studi Polder Alabio di Kabupaten Hulu Sungai Utara, Kalimantan Selatan (Sumber: Anonim, 2015b) 
Permasalahan yang sering ditemui dalam pengembangan lahan rawa, baik itu pada rawa pasang surut maupun rawa lebak adalah tata kelola air. Tata kelola air ini sangat menentukan kuantitas dan kualitas air di lahan rawa tersebut. Tata kelola air yang baik menjamin kuantitas atau ketersediaan air yang cukup di seluruh lahan dan juga kualitas air yang tidak terlalu berbeda di seluruh daerah rawa tersebut baik pada musim hujan maupun musim kemarau.

Produktivitas lahan di Polder Alabio sampai sekarang masih rendah yaitu sekitar 6.28 GKG ton/ha (Anonim, 2015b). Hal tersebut disebabkan karena saluran irigasi dan drainase yang belum berfungsi secara maksimal. Dimana masih banyak ditemui bangunan-bangunan air yang telah rusak dan tidak berfungsi. Keadaan tersebut menyebabkan ketersediaan air di wilayah Polder tersebut belum dapat menjangkau atau mengairi pada seluruh lahan. Tidak berfungsinya bangunan air di saluran irigasi dan drainase menyebabkan juga terjadinya penurunan kualitas air di lahan rawa tersebut. Oleh karena itu keadaan ini menyebabkan produktivitas lahan menjadi rendah. Disamping itu kultur budaya masyarakat alabio yang terkenal sebagai masyarakat pedagang bukan masyarakat petani (Muhaimin, 2016). Sehingga generasi-generasi muda sekarang tidak mau berprofesi sebagai petani.

Pada artikel ini dari ketiga permasalahan pada Polder Alabio tersebut yang akan diuraikan adalah terkait dengan kualitas air di lahan tersebut. Berdasarkan literatur yang telah dikumpulkan, data kualitas air secara spesifik di lahan rawa lebak Polder Alabio belum tersedia. Namun demikian secara umum, rawa lebak memang memiliki $\mathrm{pH}$ yang sedikit asam yaitu berkisar antara 3.8-4.3 (Anwar, Susilawati, \& Noor, 2012). Nilai pH yang rendah tersebut dapat menyebabkan konsentrasi logam terutama besi dan mangan yang cenderung tinggi. Kondisi ini menyebabkan tanaman pertanian terutama tanaman padi di lahan tersebut tidak tumbuh dengan baik.

Untuk mengatasi permasalahan kualitas air yang terjadi pada lahan rawa di daerah studi, harus dilakukan pengelolaan pada tata airnya terlebih dahulu. Tata air yang baik akan membantu mengatasi permasalahan pada kualitas air. Pengelolaan pada tata air di daerah studi dilakukan dengan menggunakan sistem polder. Penggunaan sistem ini ditunjukkan agar pengelolaan air dapat terkendali sepenuhnya (Rusdiansyah, Fitriati, Chandrawidjaja, \& Rahman, 2019). 
Sistem polder merupakan suatu cara penanganan drainase perkotaan dengan cara mengisolasi daerah yang dilayani terhadap masuknya air dari luar sistem baik berupa limpasan ataupun aliran bawah tanah (Solikin et al., 2017). Sistem polder dapat diartikan sebagai sebuah sistem penanganan banjir terintregasi yang memiliki elemen-elemen penting seperti tanggul keliling untuk melindungi dari air luar, stasiun pompa untuk mengontrol elelvasi air serta kolam untuk menampung sementara air yang akan dialirkan ke badan penerima air (Nugroho, 2012). Menurut Nugroho, Kurniani, Asiska, \& Nuraini (2016), sistem polder merupakan cara penanggulangan banjir dengan menggunakan bangunan fisik yang berupa sistem drainase, kolam retensi, tanggul yang mengelilingi area, dan pompa serta pintu air.

Sistem polder dijalankan dengan melakukan pengaturan air pada suatu bidang tanah dimana area tersebut dilindungi dari kerusakan akibat banjir yang berasal dari luar area (Roemiyanto, 2013). Pada sistem polder dilakukan pengaturan dan pengendalian ketinggian muka air di dalam sistem sesuai dengan rencana kebutuhan (Rahmawati, Rahmawati, Suripin, \& Kurniani, 2017). Kondisi lahan pada kawasan dapat dibiarkan pada kondisi aslinya atau dapat pula sedikit ditinggikan (Wahyuningsih, Estiana, Darsono, \& Nugroho, 2017).

Sistem polder memiliki konsukuensi dalam penggunaannya diantaranya biaya yang diperlukan sangat besar dan dalam waktu yang lama. Biaya ini digunakan untuk pembebasan tanah, pembangunan fisik dan pengadaan serta perawatan mesinmesin dan peralatan. Oleh karenanya perlu dilakukan pemeliharaan yang teratur dan sesuai dengan standar agar dapat bertahan dalam jangka waktu yang lama.

Polder Alabio merupakan suatu kawasan di Kabupaten Hulu Sungai Utara yang menggunakan sistem polder dengan mengandalkan pemberian air dari Sungai Negara. Polder Alabio mulai dilakukan pembangunan pada tahun 1933 dan terus dikembangkan hingga sekarang. Polder direncanakan dapat mengairi area persawahan seluas 6000 hektar, tetapi hingga sekarang hanya mampu mengairi sekitar 1250 hektar (D, 2017).

Polder Alabio digunakan untuk mengeluarkan dan memasukkan air untuk dapat mempertahankan muka air agar sesuai dengan keperluan. Pada Polder Alabio, terdapat pintu inlet yang terletak di Desa Sungai Mahar yang dilengkapi dengan 5 unit pompa berkekuatan 6000 liter/detik. Selain itu terdapat juga pintu 
outlet di Desa Danau Panggang yang dilengkapi dengan 5 unit pompa berkekuatan 12000 liter/detik. Pada Gambar 5 disajikan desain jaringan Polder Alabio.

Terdapat beberapa kendala dan permasalahan dalam penggunaan Polder Alabio untuk pengelolaan air pada lahan rawa di daerah studi. Permasalahan pada Polder Alabio saat ini yaitu (Anonim, 2015b):

1. Pada tanggul polder terdapat banyak pintu disekeliling polder dalam kondisi terbuka, sehingga tidak dapat berfungsi.

2. Terdapat kerusakan akibat gerusan pada sisi tanggul polder.

3. Adanya limpasan air dari Sungai Negara.

4. Penurunan kapasitan pompa irigasi dan drainase dikarenakan umur yang sudah tua.

5. Terjadi penurunan debit pada pompa irigasi dari $2.0 \mathrm{~m}^{3} /$ detik menjadi $1.2 \mathrm{~m}^{3} /$ detik.

6. Terjadi penurunan debit pada pompa drainase dari 12.5 $\mathrm{m}^{3} /$ detik menjadi $3.1 \mathrm{~m}^{3} /$ detik.
7. Terjadinya sedimentasi dan penurunan dasar saluran irigasi dan saluran drainase.

8. Hampir semua pintu di bangunan bagi dan bangunan sadap dalam kondisi rusak.

9. Terdapat sedientasi pada goronggorong.

10. Tidak tersedia fasilitas jembatan yang memadai untuk memudahkan transportasi dan mobilisasi didalam area Polder.

Berdasarkan permasalahan yang telah diidentifikasi dalam Anonim, (2015b), maka ada beberapa solusi untuk memperbaiki dan meningkatkan fungsi Polder Alabio. Solusi utama dan pertama adalah melakukan perbaikan sistem saluran meliputi saluran irigasi dan saluran drainase; perbaikan bangunan-bangunan air dan pemeliharaan saluran irigasi dan drainase secara rutin sehingga dapat berfungsi dengan baik. Apabila saluran irigasi dan drainase bisa berfungsi dengan baik, maka sirkulasi air di dalam Polder Alabio tersebut bisa berlangsung dengan baik, yang berakibat pada kualitas air yang semakin baik. 


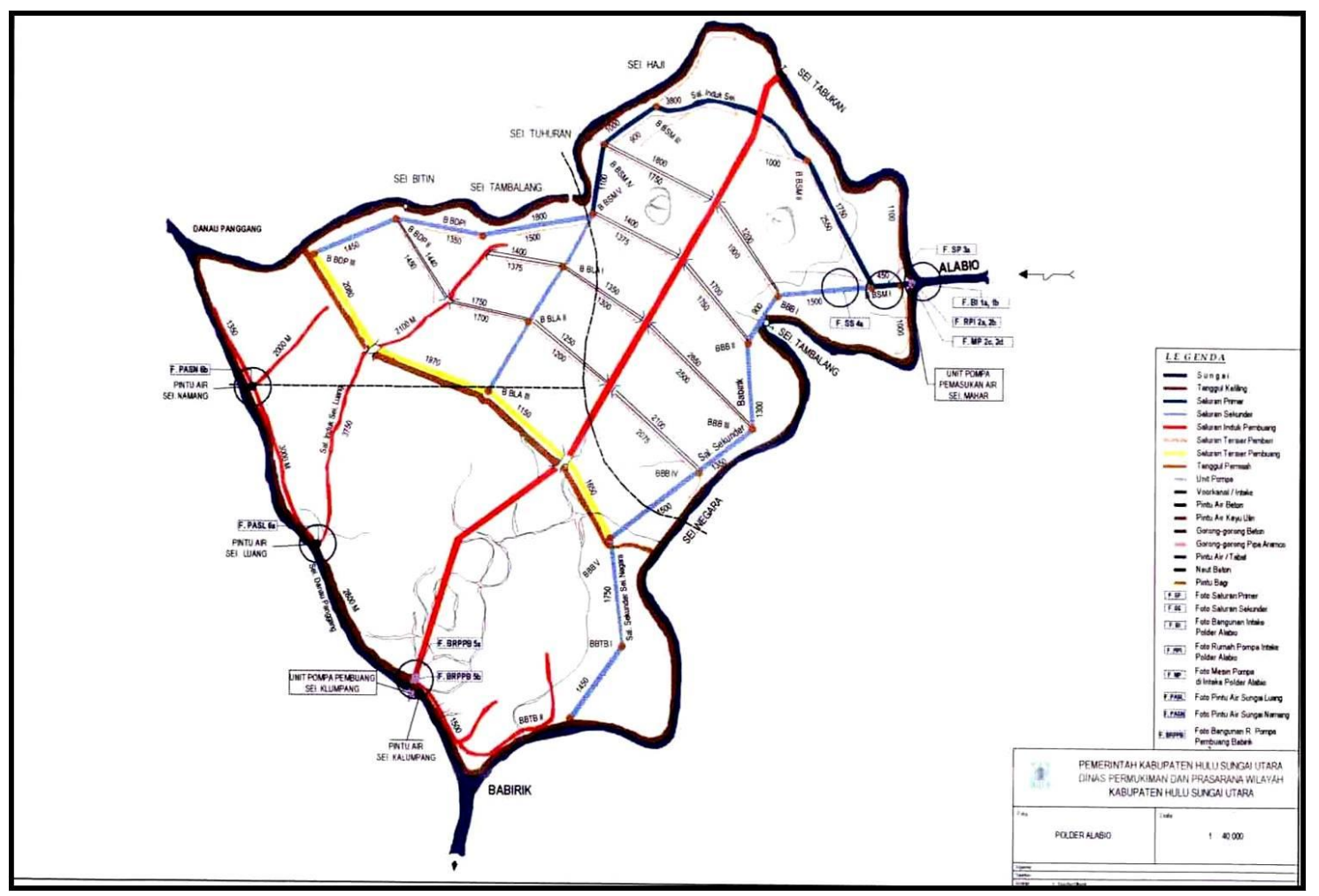

Gambar 5. Desain Jaringan Tata Air Polder Alabio

(Sumber: Noor et al., 2019)

\section{SIMPULAN DAN SARAN}

\subsection{Simpulan}

Hasil studi menunjukkan bahwa pengelolaan air pada Polder Alabio masih belum berfungsi secara optimal. Permasalahan utama pada pengembangan Polder Alabio adalah pada sistem saluran irigasi, drainase dan bangunan-bangunan air yang belum berfungsi dengan baik, serta pemeliharaan yang belum dilakukan dengan rutin dan baik. Saluran irigasi, drainase dan bangunan air yang tidak berfungsi dengan baik menyebabkan kuantitas air (debit) belum bisa dialirkan dengan baik pada seluruh lahan sehingga berdampak juga pada kualitas air di lahan yang kurang baik. Beberapa solusi yang dapat dilakukan untuk mengatasi permasalahan pada Polder Alabio adalah dengan melakukan perbaikan dan pemeliharaan secara rutin dan berkala pada saluran irigasi dan saluran drainase serta pemeliharaan terhadap bangunan-bangunan air yang ada di Polder Alabio tersebut.

\subsection{Saran}

Saran dari studi ini adalah perlu dilakukan studi khusus yaitu SID (survey investigation design) untuk lahan rawa Polder Alabio, sehingga perbaikan dalam pengembangan lahan rawa Polder Alabio lebih tepat. 


\section{DAFTAR PUSTAKA}

Anonim. (2012). SNI 1726:2012 tentang Tata Cara Perencanaan Ketahanan Gempa untuk Struktur Bangunan Gedung dan Non Gedung. Jakarta: Badan Standardisasi Nasional.

Anonim. (2015a). Peraturan Pemerintah Nomor 29 Tahun 2015 Tentang Rawa. Jakarta: Kementerian Pekerjaan Umum dan Perumahan Rakyat.

Anonim. (2015b). PIRIMP Participatory Irrigation Rehabilitation Improvement Management Project: Sub-Proyek - Alabio di Kalimantan Selatan. Direktorat Jenderal Sumber Daya Air. Nippon Koei Co., Ltd. In association with PT. Virama Karya, PT. Indra Karya, PT. Tata Guna Patria, PT. Kwarsa Hexagon, PT. Wiratman \& Associate.

Anwar, K., Susilawati, A., \& Noor, M. (2012). Laporan Hasil Penelitian Tahun Anggaran 2012-2013. Balai Penelitian Lahan Rawa.

Arfiadi, Y. (2016). Diagram Interaksi Perencanaan Kolom dengan Tulangan pada Empat Sisi Berdasarkan SNI 2847:2013 dan ACI 318M-11. Jurnal Teknik Sipil, 13(4), 268-290.

D, Y. R. (2017). Dinamika Kelompok Perkumpulan Petani Pemakai Air di Lahan Rawa Lebak. SEPA: Jurnal Sosial Ekonomi Pertanian Dan Agribisnis, $\quad 11(2), \quad 235$. https://doi.org/10.20961/sepa.v11i2.1 4186

Djamhari, S. (2009). Penerapan Teknologi Pengelolaan Air di Rawa Lebak Sebagai Usaha Peningkatan Indeks Tanam di Kabupaten Muara Enim. Jurnal Hidrosfir Indonesia, 4(1), 2328.
Fuadi, R. A., Daud, S., \& Peratenta, M. (2015). Pengaruh Konsentrasi Chemical Agent (Detergent, $\mathrm{NaOH}$ ) dan Tekanan Trans-Membran pada Pencucian Membran dari Proses Pengolahan Air Gambut Secara Cross Flow. JOM FTEKNIK, 2(2), 1-6.

Irwandi, D. (2015). Analisis Sistem Komunikasi Usaha Tani Padi-Jeruk di Lahan Pasang Surut Kalimantan Tengah. Agrica Ekstensia, 9(1), 8-15.

Muhaimin. (2016). Bisnis Wirausahawan Muslim Alabio Studi Kasus di Kota Banjarmasin. International Conference on Social and Intellectual Transformation of the Contemporary Banjarese, 1-19.

Noor, M., Anwar, K., \& Kartiwa, B. (2019). Sistem Polder untuk Pengembangan Pertanian Berkelanjutan di Lahan Rawa Lebak.

Nugroho, H., Kurniani, D., Asiska, M., \& Nuraini, N. (2016). Kajian Kinerja Sistem Polder sebagai Model Pengembangan Drainase Kota Semarang Bagian Bawah dengan Balanced Scorecard. MEDIA KOMUNIKASI TEKNIK SIPIL, 22(1), 43. https://doi.org/10.14710/mkts.v22i1. 12508

Nugroho, V. (2012). Evaluasi Sistem Polder Kota Lama dan Bandarharjo Semarang Terhadap Pengendalian Banjir dan Ron. Surakarta: Universitas Sebelas Maret.

Rahmawati, E., Rahmawati, A. W., Suripin, S., \& Kurniani, D. (2017). Pegembangan Drainase Sistem Polder Sungai Sringin ota Semarang. Jurnal Karya Teknik Sipil, 6(1), 281290.

Rianto, N. (2012). Penyusunan Aspek Organisasional Pengelola Polder 
Studi Kasus: Kali Banger, Kota Semarang. Widyariset, 15(1), 39-48.

Roemiyanto, F. M. (2013). Konsep Teknologi Sistem Polder untuk Pelestarian Stasiun Semarang Tawang. Jurnal Teknik Sipil, 6(1), 17.

Rusdiansyah, A., Fitriati, U., Chandrawidjaja, R., \& Rahman, A. A. (2019). Dasar Pengembangan Lahan Rawa. Banjarmasin: Lambung Mangkurat University Press.

Solikin, Suhartanto, E., \& Haribowo, R. (2017). Penanganan Genangan dengan Sistem Polder pada Wilayah Kota Banjarmasin. Jurnal Teknik Pengairan, 8(1), 15-25.

Sulaeman, Y., Poggio, L., Minasny, B., \& Nursyamsi, D. (2018). Tropical Wetlandsa-Innovation in Mapping and Management. Proceedings of the International Workshop in Mmapping and Management, 210. Banjarmasin: CRC Press.

Suriadikarta, D. A. (2012). Teknologi Pengelolaan Lahan Rawa Berkelanjutan: Studi Kasus Kawasan Ex PLG Kalimantan Tengah. Jurnal Sumberdaya Lahan, 6(1), 45-54.

Wahyuningsih, C. A., Estiana, R., Darsono, S., \& Nugroho, H. (2017). Perencanaan Sistem Polder Tambak Lorok Semarang Utara. Jurnal Karya Teknik Sipil, 6(1), 314-323.

Zulfan, J., \& Hana, M. A. (2013). Pengelolaan Polder Banger Berbasis Kebersamaan Antar Stakeholder. Jurnal Sosial Ekonomi Pekerjaan Umum, 5(1), 39-50. 